\title{
ESTIMATION OF TRAP EFFICIENCY OF SRIRAMSAGAR RESERVOIR
}

\author{
Qamar Sultana ${ }^{1}$, M. Gopal Naik ${ }^{2}$ \\ ${ }^{I}$ Assistant Professor, Muffakham Jah College of Engineering \& Tech \& Research Scholar, UCE, OU \\ ${ }^{2}$ Professor of Civil Engineering, University College of Engineering (UCE) OU, Hyderabad,
}

\begin{abstract}
Reservoirs all over the world undergo the flow of sediment and deposition in it over a period of time which causes a reduction in their capacity. The estimation of sedimentation in the reservoirs has become a significant problem. There are a number of methods to estimate the sediment deposited in the reservoir. However, each method varies greatly in its own way in its complexity, inputs and other requirements. The simple way to determine the quantity of sediment deposited in the reservoir can be done through the knowledge of the trap efficiency of the reservoir. Trap efficiency $\left(T_{e}\right)$ is the proportion of the stream sediment that is trapped in the reservoir. Many of the trap efficiency estimation methods establishes a relationship of the trap efficiency to their capacity and annual inflow, generally through curves. In this study, the empirical relationships given by Brown, Gill and Brune were used for estimating the trap efficiency of Sriramsagar reservoir on Godavari river in Nizambad district of Telangana State, in India and compared with the observed trap efficiency of the reservoir. It is found that the trend of the results of Gill's and Brune's method for medium sediment followed that of the observed $T_{e}$ and it is also observed that the results of the values of the $T_{e}$ estimated by the Brown's method with $K=1$ is found to be best suited for estimating the $T_{e}$ for the reservoir. It is also seen that, the major advantage of these empirical methods is to give fairly reasonable results from very limited data that is capacity, average annual inflow and catchment area.
\end{abstract}

Keywords: Sedimentation of Reservoirs, Empirical method, Trap Efficiency method, Brown's, Gill's and Brune's method.

\section{INTRODUCTION}

From the early times of the existence of the man, he has been trying to save the water available on the surface of the earth by constructing some structures called dams to impound water, which is called as a reservoir. Another reason for the creation of a reservoir was to make the water available where and when needed. And the available water was used to meet the various requirements such as irrigation of crops, drinking water supply, hydropower generation. Many researchers have made an attempt to estimate the storage capacity of the reservoirs all over the world. Yang, 2003 stated one such estimation as 4000 to $6000 \times 109 \mathrm{~m}^{3}$, and another as 5 per cent of the total runoff in the world $\left(38830 \times 109 \mathrm{~m}^{3}\right)$, i.e. $2000 \times 109 \mathrm{~m}^{3}$. Siyam et al. 2005 , stated that the potential quantity of water that can be controlled in the future through the reservoirs varies between 9000 and $14000 \mathrm{~km}^{3}$ annually. Thus these storage reservoirs are the primary structures for mankind survival and well being.

In addition to the innumerable benefits, there are also a number of demerits of the reservoirs. Significant demerits are the disturbances to the natural flow of the rivers, disturbance to the natural eco-systems, resettlement or relocation of the people due to land inundation and reservoir sedimentation. Reservoir Sedimentation is the filling of the reservoir with the sediment that is brought by the stream from the watersheds. This process takes place as the construction of the dam or the barrier reduces the velocity of the flowing stream and subsequently the turbulence gets reduced, which causes the flowing sediments to settle down. The sedimentation of the reservoir causes the problems of the loss of storage capacity of the reservoir, hindrance in the generation of the hydropower and the problems in the operation and the maintenance of the reservoir which in turn increases the cost of maintenance of the reservoir. Reservoir sedimentation has become a significant problem all over the world, because it is affecting the reservoir capacity and the very purpose for which it is being created is not met. The cost of the removal of the accumulated sediment is very high and hence managing and minimizing of this accumulated reservoir sediment has become a necessity. Therefore the knowledge of the quantity of the sediments accumulating in a reservoir with time and the knowledge of the various methods available for the estimation of the sediments has become a necessity.

Reservoir sedimentation is caused due to many reasons. The important factors effecting the reservoir sedimentation are the watershed, sediment and river characteristics. According to Arora and Goel, 1994, the significant factors influencing the rate of siltation in a reservoir are: (a) Capacity to Inflow Ratio (C/I), (b) sediment content in the flowing water, (c) texture and size of the sediment, $(\mathrm{d})$ trap efficiency $\left(\mathrm{T}_{\mathrm{e}}\right)$ of the reservoir, and (e) the reservoir operation method. According to Yoon, 1992; Yang, 2003, the annual loss of the reservoir storage capacity due to sedimentation all over 
the world is estimated at 1 to 2 per cent of the total reservoir storage capacity. The sedimentation rate is not the same for all the reservoirs of the world. The sedimentation rate is very high for some reservoirs and are filled very rapidly, while it is negligible for others and they are hardly affected by sedimentation. According to Shangle, 1991, the sedimentation survey in India of 43 major, medium and minor reservoirs shows that the sedimentation rate varies between 0.34 to 27.85 ha $\mathrm{m} / 100 \mathrm{~km}^{2} /$ year for major reservoirs, 0.15 to $10.65 \mathrm{ha} \mathrm{m} / 100 \mathrm{~km}^{2} /$ year for medium reservoirs and 1.0 to $2.3 \mathrm{ha} \mathrm{m} / 100 \mathrm{~km}^{2} /$ year for minor reservoirs.

Many empirical studies have been done for the estimation of reservoir sedimentation by many researchers since 1950 and several methods have been given by them. One of these methods is trap efficiency method proposed by Brune, 1953; Gill, 1979; Dendy, 1974; Heinemann, 1981; Jothiprakash and Garg, 2008 and it is seen from their work that trap efficiency method is a simple and best method.

\section{STUDY AREA DESCRIPTION}

The Sriramsagar Project (SRSP), formerly known as the Pochampadu irrigation project has been built on Godavari river which is one of the major peninsular rivers in southern India. This project is located at Pochampadu village $\left(18^{\circ}-\right.$ $58^{\prime} \mathrm{N}$ latitude and $78^{\circ}-20^{\prime} \mathrm{E}$ longitudes) in Nizamabad district of Telangana State (TS) of southern India at a distance of about $200 \mathrm{Km}$ from Hyderabad city. The SRSP project has been built to utilize Godavari river water for irrigation and drinking purposes in Telangana state. The regions such as Nizamabad, Adilabad, Karimnagar, and Warangal districts of Telangana State are covered under this project. The Sriramsagar reservoir is a major project built on the Godavari river at its 637th $\mathrm{Km}$ for the irrigation facilities to about 4.0lakhs hectares in addition to generate power up to $36 \mathrm{M}$.W.

The sediment inflow and outflow data for the Sriramsagar reservoir were collected from CWC (Central Water Commission), A.C.Guards, Hyderabad for the period of 25 years. The reservoir capacity, reservoir annual inflows and reservoir outflows data were obtained from SRSP -I (Sriramsagar Camp) Office, Erram-Munzil, Hyderabad and the reservoir sedimentation data were obtained from A.P.E.R.L (A. P. Engineering Research Labs), Rajendranagar Hyderabad.

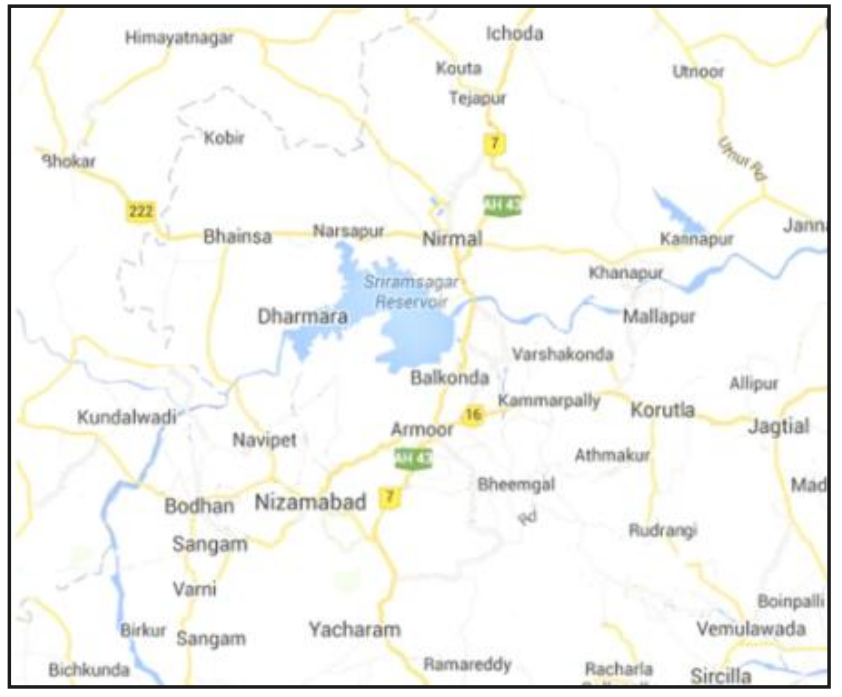

Fig 1 Index Map Source: APERL

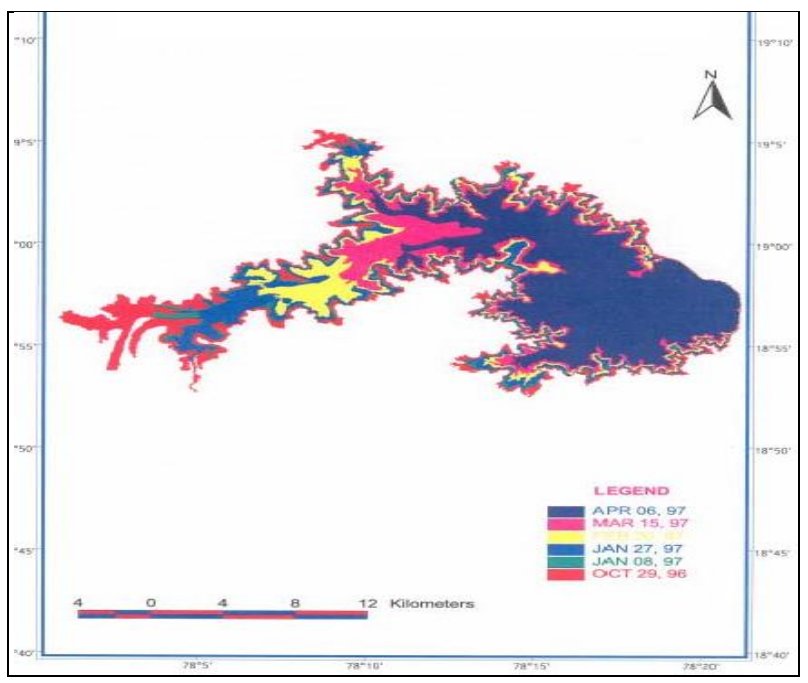

Fig.2 Superimposed Water Spread Area -Source: APERL

\section{METHODOLOGY}

\subsection{Trap efficiency $\left(T_{e}\right)$ and its Estimation}

Trap Efficiency: Trap efficiency $\left(\mathrm{T}_{\mathrm{e}}\right)$ is the proportion of the stream sediment that is trapped in the reservoir.

\subsection{Methods of Estimating Trap Efficiency $\left(T_{e}\right)$}

\subsubsection{Heinemann's Method}

According to Heinemann, 1981; trapping efficiency is the most informative descriptor of a reservoir. He described this value as the ratio of sediment retained within the reservoir to the sediment inflow of the reservoir expressed as a percentage as given in equation 1 .

$$
\mathrm{T}_{\mathrm{e}}=\left[\frac{\mathrm{V}_{\mathrm{i}}-\mathrm{V}_{0}}{\mathrm{~V}_{\mathrm{i}}}\right] \times 100 \%
$$

where, $V_{i}$ is the volume of sediment inflow, $V_{O}$ is the volume of sediment outflow. According to Morris and Fan, 1998; Verstraeten and Poesen, 2000; Campos, 2001; Yang, 2003; the trap efficiency $\mathrm{T}_{\mathrm{e}}$ is dependent on several 
parameters, like the size and the distribution of the sediment, the time and rate of water inflow into the reservoir, the reservoir size and shape, the location of the outlet structure and water discharge schedules. From the literature review it is observed that the empirical studies have been done by Brown, 1944; Churchill, 1948; Brune, 1953; showing the relation between the reservoir storage capacity, water inflow, and trapping efficiency. These methods define a relationship of $\mathrm{T}_{\mathrm{e}}$ with the capacity and average annual inflow parameters of the reservoir, generally through curves.

\subsubsection{Brown's Method}

The first trap efficiency $\left(\mathrm{T}_{\mathrm{e}}\right)$ estimation method was the pioneer work by Brown in 1944. USACE (1989) named this method as Capacity-Watershed method because Brown's curve relates the ratio of the reservoir capacity and the catchment or the watershed area (C/A) to the trap efficiency $\left(T_{e}\right)$. The figure 3 . curve can be represented by the equation 2. for estimating the value of trap efficiency $\mathrm{T}_{\mathrm{e}}$ (Gill, 1979; Campos, 2001; USACE, 1989)

$$
\mathrm{Te}=1-\frac{1}{\left[1+\mathrm{K}\left(\frac{\mathrm{C}}{\mathrm{A}}\right)\right]}
$$

where $\mathrm{C}$, is capacity of the reservoir, $\mathrm{A}$ is the area of the catchment above the reservoir and $\mathrm{K}$ is a coefficient whose value varies from 0.046 to 1.0 depending upon different factors. According to USACE (1989), (i) K increases with the smaller and varied retention time, (ii) $\mathrm{K}$ increases as the average grain size increases and (iii) $\mathrm{K}$ increases with reservoir operation that prevents release of sediment through sluicing or prevents the movement of sediment towards the outlets by pool elevation regulation. A value of $\mathrm{K}=0.1$ is recommended for average conditions, and values of $\mathrm{K}=1.0$ for coarse sediment; $\mathrm{K}=0.1$ for medium sediment; and $\mathrm{K}=0.046$ for fine sediment is recommended (Gill, 1979). The Brown's method is more simpler as only two parameters i.e., catchment area and reservoir capacity are required for the estimation of the trap efficiency.

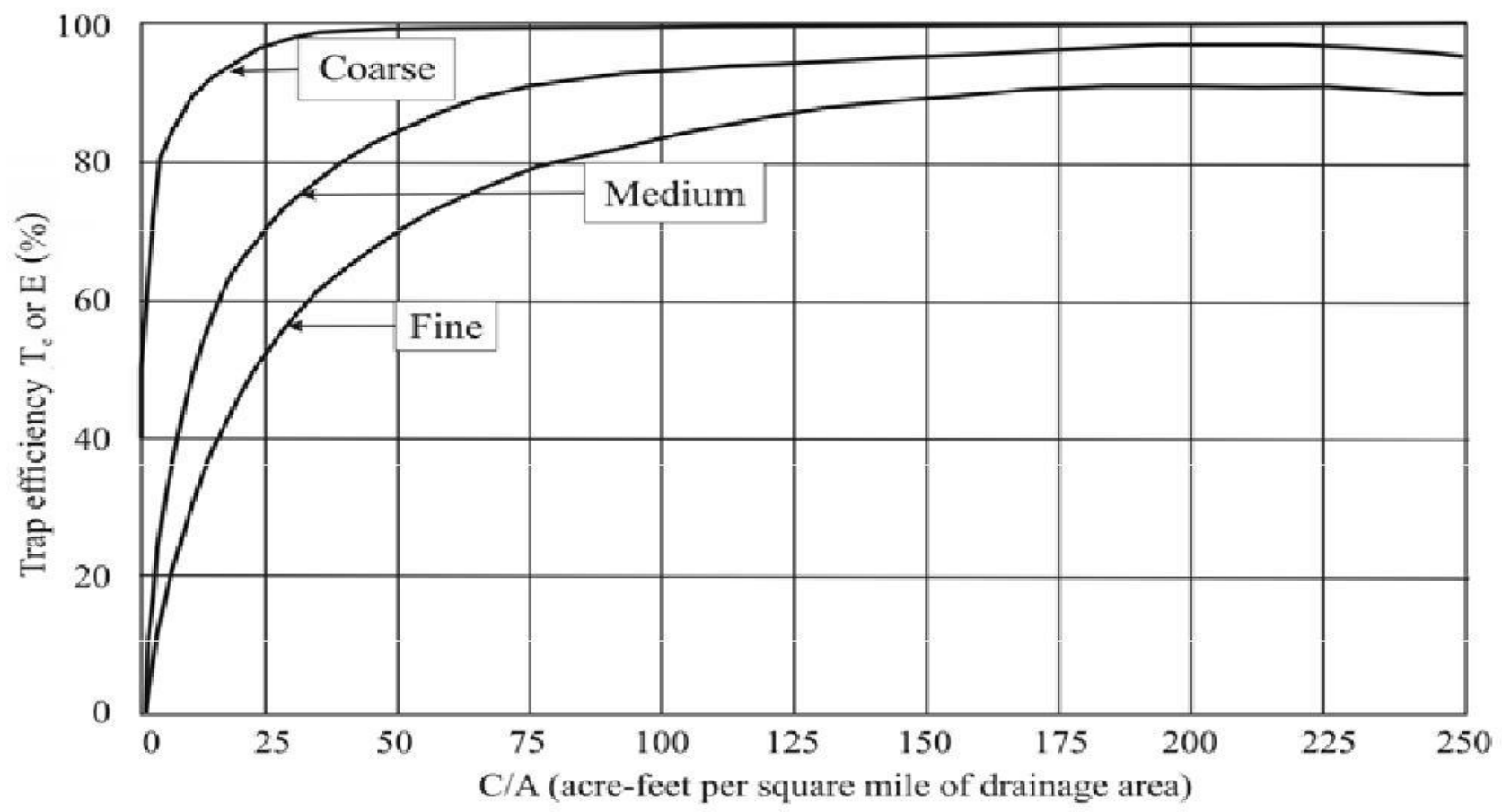

Fig. 3 Brown's (1944) trap efficiency curve (USACE, 1989)

After Brown's method, the next method for Te prediction was Churchill's (1948) method.

\subsubsection{Churchill's Curve (Sediment Index Method)}

Churchill (1948) developed a relationship between the sedimentation index $(\mathrm{SI})$ and the trap efficiency $\left(\mathrm{T}_{\mathrm{e}}\right)$. The sedimentation index is the ratio of the retention time and reservoir mean velocity.

Sedimentation Index(S. I. ) =Period of Retention(R)/ Mean Velocity(V)
If the retention time or mean velocity is not available from the field, it can be taken as the retention time as computed by using the $\mathrm{C} / \mathrm{I}$ ratio. The period of retention $(\mathrm{R})$, the mean velocity $(\mathrm{V})$ can be computed using the below mathematical equations.

$$
\begin{aligned}
& \mathrm{R}=\mathrm{C} / \mathrm{I} \\
& \mathrm{V}=\mathrm{I} / \mathrm{A} \\
& \mathrm{A}=\mathrm{C} / \mathrm{L}
\end{aligned}
$$

$$
\text { S. I. }=\mathrm{CA} / \mathrm{I}^{2}=\left(\mathrm{C} / \mathrm{I}^{2}\right)(\mathrm{C} / \mathrm{L})=(\mathrm{C} / \mathrm{I})^{2} / \mathrm{L}
$$


where

S.I - is the Sedimentation Index

$\mathrm{R}$ - is the Retention Time

C- is the Capacity

A- is the Cross Sectional Area

$\mathrm{V}$ - is the mean velocity

$\mathrm{L}$-is the reservoir length

$\mathrm{I}$ - is the reservoir inflows

Two curves were defined by Churchill, one for the fine silt discharged from a reservoir and the other for the sediment originated in the catchment called as the local silt. According to Morris and Fan, 1998; Murthy, 1980, the drawback of the Churchill's method is that it is limited to the estimation of the sediments in settling basins, small reservoirs.

Following Churchill, the next method to estimate $\mathrm{T}_{\mathrm{e}}$ was Brune (1953).

\subsubsection{Brune's Curve (Capacity-Inflow Method)}

Brune's curve method is most common method used for determining the trap efficiency of reservoirs. Brune drew the curves using the data from 44 normal ponded reservoirs in the United States and plotted $\mathrm{T}_{\mathrm{e}}$ against the reservoir $\mathrm{C} / \mathrm{I}$ ratio. Brune plotted three curves consisting of one median and two envelop curves as shown in the figure 4. Brune developed an empirical relationship between trap efficiency and the ratio of reservoir capacity to the annual inflow which is shown in the equations $3 \& 4$.

Brune's Curve for

(i) Coarse grained sediments.

$$
\begin{aligned}
& \mathrm{Te}=\frac{8000-36\left(\frac{\mathrm{C}}{\mathrm{I}}\right)^{-0.78}}{78.85+\left(\frac{\mathrm{C}}{\mathrm{I}}\right)^{-0.78}} \\
& \text { (ii) } \quad \text { Medium grained sediments. } \\
& \mathrm{Te}=\frac{\left(\frac{\mathrm{C}}{\mathrm{I}}\right)}{0.00013+0.01\left(\frac{\mathrm{C}}{\mathrm{I}}\right)+0.0000166 \sqrt{\frac{\mathrm{C}}{\mathrm{I}}}}
\end{aligned}
$$

The difference in the curves or the equations is because of the same factors that influence the K coefficient in Brown's curve. In comparison to the Brown's curve, the Brune's curve is considered to be more accurate.

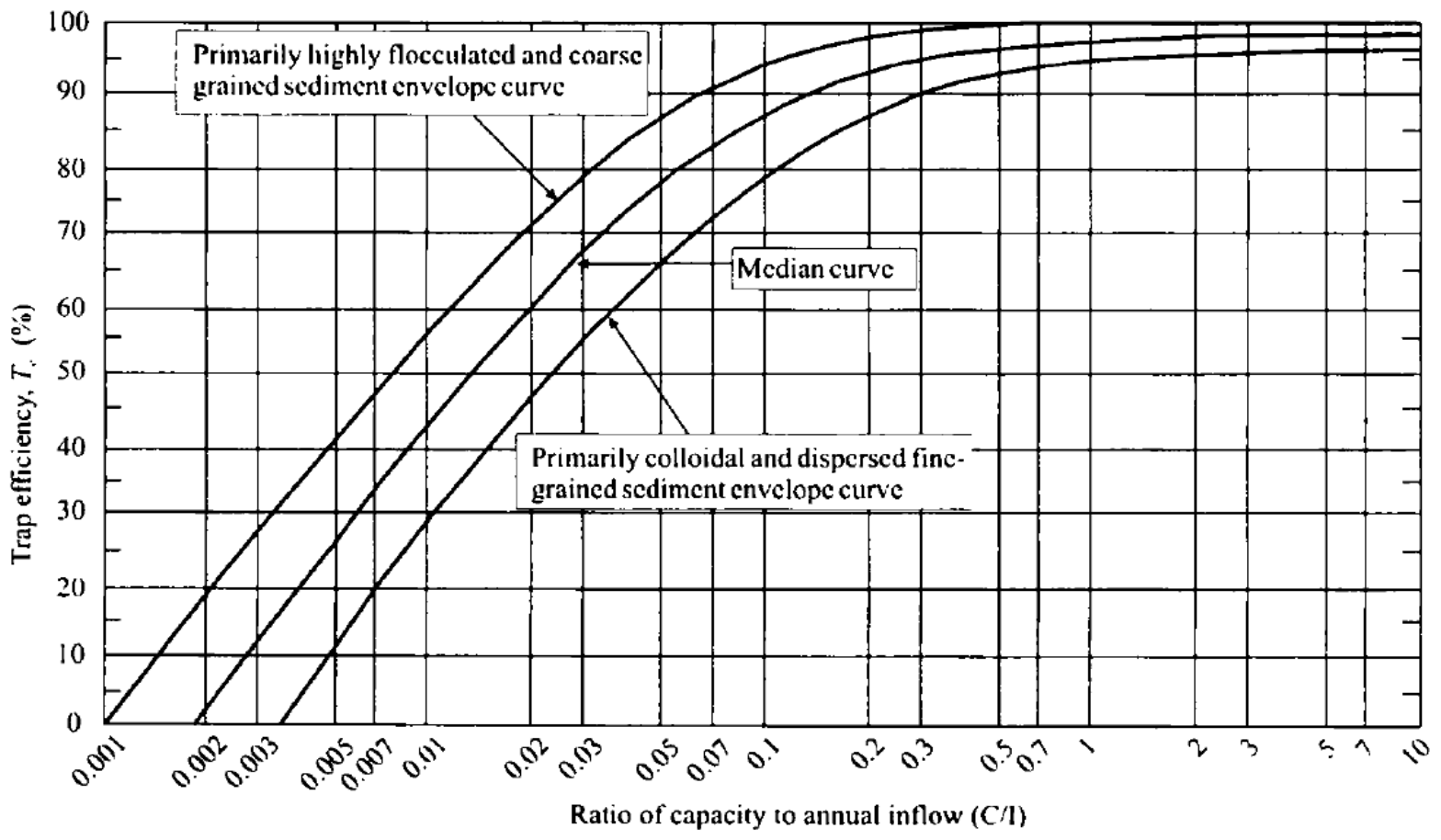

Fig. 4 sediment trapping efficiency as per Brune (1953)

Heinmann (1981) developed Brune method as

$$
\mathrm{T}_{\mathrm{e}}=100 \times\left[\frac{\mathrm{K}}{0.012+1.02 \mathrm{~K}}\right]
$$

Where,

$\mathrm{K}=\mathrm{S} . \mathrm{I} \mathbf{x} \mathrm{g}$ where

$\mathrm{g}$ is the acceleration due to gravity

S.I is the sedimentation index which can be determined using the expression

$$
\text { S.I }=\frac{\left(\frac{C}{I}\right)^{2}}{L}
$$


Where,

$\mathrm{L}=$ the reservoir length

A best fit equation based on the Brune's Coarse Grained Sediments envelope curve was developed for Gobind Sagar Reservoir to calculate the trap efficiency by Jothiprakash and Garg (2008) as shown in the equation 6.

$$
\mathrm{T}_{\mathrm{e}}=\frac{\left(\frac{\mathrm{C}}{\mathrm{I}}\right)^{2}}{\left(\frac{\mathrm{C}}{\mathrm{I}}\right)^{2}+0.0025 \times\left(\frac{\mathrm{C}}{\mathrm{I}}\right)+0.00003}
$$

Based on the three curves proposed by Brune, Gill (1979) developed empirical equations which provided a very close fit to the curves( Jothiprakash and Garg , 2008).

(i) For coarse grained sediments:

$$
\mathrm{T}_{\mathrm{e}}=\frac{\left(\frac{\mathrm{C}}{\mathrm{I}}\right)^{2}}{0.994701\left(\frac{\mathrm{C}}{\mathrm{I}}\right)^{2}+0.006297\left(\frac{\mathrm{C}}{\mathrm{I}}\right)+0.3 \times 10^{-5}}
$$

(ii) For medium grained sediments (Morris and Wiggert, 1972):

$$
\mathrm{Te}=\frac{\left(\frac{\mathrm{C}}{\mathrm{I}}\right)}{0.012+1.02\left(\frac{\mathrm{C}}{\mathrm{I}}\right)}
$$

(iii) For colloidal and dispersed fine-grained sediments:

$$
\mathrm{T}_{\mathrm{e}}=\frac{\left(\frac{\mathrm{C}}{\mathrm{I}}\right)^{3}}{1.02655\left(\frac{\mathrm{C}}{\mathrm{I}}\right)^{3}+0.02621\left(\frac{\mathrm{C}}{\mathrm{I}}\right)^{2}-0.133 \times 10^{3}\left(\frac{\mathrm{C}}{\mathrm{I}}\right)+0.1 \times 10^{-5}}(\text { Eqn.9) }
$$

In the present study, trap efficiency of Sriramsagar reservoir across the river Godavari in Telangana State, India is estimated using Brown (1944), Gill(1979) and Brune (1953) approach and is compared with the observed trap efficiency calculated using the equation. 1

\section{RESULTS AND DISCUSSIONS}

The trap efficiencies calculated by using the different methods and the observed trap efficiency is shown in the table1. The observed trap efficiency is calculated using the equation 1. as suggested by Heinemann(1981) which uses the parameters, volume of sediment inflow into and sediment outflow from the reservoir. The trap efficiency by Brown method is determined by using the equation 2. which uses the capacity-area ratio and the $\mathrm{K}$ factor whose value is adopted as 1 as $\mathrm{K}=0.1$ is showing underestimated values. The trap efficiency by Brune method is obtained using the equation 4 . which uses the capacity-inflow ratio for medium sediment depending upon the size of the reservoir. The trap efficiency by Gill method is obtained by using the equation 8 which is for medium sediment.



\begin{tabular}{|c|c|c|c|c|c|c|c|c|}
\hline Year & $\begin{array}{l}\text { Capacity } \\
(C \text { in } \\
\left.\mathbf{x 1 0}^{6} \mathrm{~m}^{\mathbf{3}}\right)\end{array}$ & $\begin{array}{l}\text { Annual } \\
\text { Inflows } \\
\text { (I in } \\
\text { Mcum) }\end{array}$ & $\begin{array}{l}(\mathrm{C} / \mathrm{I} \\
\text { Ratio }\end{array}$ & $\begin{array}{l}\text { (C/A) } \\
\text { Ratio }\end{array}$ & $\begin{array}{l}\mathrm{T}_{\mathrm{e}} \quad(\%) \\
\text { Brown } \\
\text { Method } \\
(\mathbf{k}=1)\end{array}$ & $\begin{array}{l}\mathrm{T}_{\mathrm{e}} \quad(\%) \\
\text { Gill } \\
\text { Method } \\
\text { (Medium } \\
\text { Sediments) }\end{array}$ & $\begin{array}{l}\mathrm{T}_{\mathrm{e}} \quad(\%) \\
\text { Brune } \\
\text { Method } \\
\text { (Medium } \\
\text { Sediments) }\end{array}$ & $\begin{array}{l}\mathrm{T}_{\mathrm{e}} \quad(\%) \\
\text { Observed }\end{array}$ \\
\hline 1987 & 2377.37 & 4593.95 & 0.52 & 5.47 & 84.54 & 95.86 & 97.33 & 97.76 \\
\hline
\end{tabular}

Fig. 5 Comparative plot of $\mathrm{Te}(\%)$ estimation with different methods

Catchment Area of Sriramsagar Reservoir $=434.88 \mathrm{~m}^{2}$

Table 1 Comparison of Observed and Estimated Trap efficiencies by different methods 


\begin{tabular}{|l|l|l|l|l|l|l|l|l|}
\hline $\mathbf{1 9 8 8}$ & 2377.37 & 3215.82 & 0.74 & 5.47 & 84.54 & 96.50 & 98.09 & 82.74 \\
\hline $\mathbf{1 9 8 9}$ & 2377.37 & 25900.39 & 0.09 & 5.47 & 84.54 & 86.90 & 87.18 & 99.99 \\
\hline $\mathbf{1 9 9 0}$ & 2377.37 & 16351.96 & 0.15 & 5.47 & 84.54 & 90.70 & 91.43 & 60.19 \\
\hline $\mathbf{1 9 9 1}$ & 2377.37 & 19509.94 & 0.12 & 5.47 & 84.54 & 89.41 & 89.97 & 75.24 \\
\hline $\mathbf{1 9 9 2}$ & 2377.37 & 4863.10 & 0.49 & 5.47 & 84.54 & 95.74 & 97.18 & 92.91 \\
\hline $\mathbf{1 9 9 3}$ & 2377.37 & 1666.60 & 1.43 & 5.47 & 84.54 & 97.24 & 98.96 & 90.86 \\
\hline $\mathbf{1 9 9 4}$ & 2377.37 & 2775.15 & 0.86 & 5.47 & 84.54 & 96.71 & 98.33 & 89.54 \\
\hline $\mathbf{1 9 9 5}$ & 2557.25 & 3586.79 & 0.71 & 5.88 & 85.47 & 96.45 & 98.02 & 86.33 \\
\hline $\mathbf{1 9 9 6}$ & 2557.25 & 6815.24 & 0.38 & 5.88 & 85.47 & 95.06 & 96.40 & 90.67 \\
\hline $\mathbf{1 9 9 7}$ & 2557.25 & 4049.05 & 0.63 & 5.88 & 85.47 & 96.25 & 97.78 & 96.01 \\
\hline $\mathbf{1 9 9 8}$ & 2557.25 & 1583.05 & 1.62 & 5.88 & 85.47 & 97.33 & 99.07 & 93.11 \\
\hline $\mathbf{1 9 9 9}$ & 2557.25 & 15672.72 & 0.16 & 5.88 & 85.47 & 91.45 & 92.27 & 89.47 \\
\hline $\mathbf{2 0 0 0}$ & 2557.25 & 6815.07 & 0.38 & 5.88 & 85.47 & 95.06 & 96.40 & 81.72 \\
\hline $\mathbf{2 0 0 1}$ & 2557.25 & 9185.72 & 0.28 & 5.88 & 85.47 & 94.06 & 95.25 & 94.26 \\
\hline $\mathbf{2 0 0 2}$ & 2557.25 & 2947.73 & 0.87 & 5.88 & 85.47 & 96.73 & 98.35 & 86.33 \\
\hline $\mathbf{2 0 0 3}$ & 2557.25 & 3505.65 & 0.73 & 5.88 & 85.47 & 96.48 & 98.06 & 41.80 \\
\hline $\mathbf{2 0 0 4}$ & 2557.25 & 3147.25 & 0.81 & 5.88 & 85.47 & 96.64 & 98.25 & 94.07 \\
\hline $\mathbf{2 0 0 5}$ & 2557.25 & 541.16 & 4.73 & 5.88 & 85.47 & 97.80 & 99.65 & 80.88 \\
\hline $\mathbf{2 0 0 6}$ & 2264.15 & 10622.35 & 0.21 & 5.21 & 83.89 & 92.91 & 93.93 & 91.25 \\
\hline $\mathbf{2 0 0 7}$ & 2264.15 & 14625.44 & 0.15 & 5.21 & 83.89 & 91.11 & 91.90 & 98.91 \\
\hline $\mathbf{2 0 0 8}$ & 2264.15 & 2920.04 & 0.78 & 5.21 & 83.89 & 96.57 & 98.17 & 92.84 \\
\hline $\mathbf{2 0 0 9}$ & 2264.15 & 3707.05 & 0.61 & 5.21 & 83.89 & 96.19 & 97.71 & 97.99 \\
\hline $\mathbf{2 0 1 0}$ & 2264.15 & 1061.09 & 2.13 & 5.21 & 83.89 & 97.50 & 99.28 & 86.07 \\
\hline $\mathbf{2 0 1 1}$ & 2264.15 & 8848.57 & 0.26 & 5.21 & 83.89 & 93.73 & 94.87 & 90.67 \\
\hline $\mathbf{2 0 1 2}$ & 2264.15 & 4896.58 & 0.46 & 5.21 & 83.89 & 95.61 & 97.04 & 63.10 \\
\hline Average & & & & & 84.75 & 94.85 & 96.19 & 86.34 \\
\hline
\end{tabular}

\section{CONCLUSION}

The sediment trap efficiency $\left(T_{e}\right)$ of the Sriramsagar reservoir located on Godavari river in Nizambad district, Telangana State of India is being estimated using Brown's ,Gill's and Brune's methods. The trap efficiency $\left(T_{e}\right)$ is estimated using the Brown's method with $\mathrm{K}=1.0$, Gill's and Brune's method for medium sediment . It is found that the trend of the results of the Gill's and Brune's method for medium sediment followed that of the observed trap efficiencies as seen from the figure 5. The results of the trap efficiency estimated by Brown's method with $\mathrm{K}=1$ were found to be well suitable for the estimation of the trap efficiency values for the reservoir which is shown in the table 1. It is also seen that, the major advantage of these empirical methods is to give fairly reasonable results from very limited data, that is the storage volume, average annual inflow and catchment area. The only drawback of these methods is that the data over a long period is required for good results. In a country like India where the measured data of the sediment inflow and outflow data are not available, these empirical approaches are the best suitable approach to estimate sediment retention in the reservoirs.

\section{REFERENCES}

[1]. Arora, P. K. and Goel, M. P. (1994). "Estimating life of a reservoir." Proc. Reservoir Sedimentation, May 17-19, 411.
[2]. Brown, C.B. (1944). "Discussion of Sedimentation in Reservoirs.Ed. J. Wittig.", Proc. American Society of Civil Engineers, 69, 1493-1500.

[3]. Brown, C.B. (1950). Sediment transportation: Engg hydraulics, chapter 8.

[4]. Brune, G.M. (1953). "Trap Efficiency of Reservoirs." , Trans. Am. Geophysical Union, 34 (3), 407-418.

[5]. Campos, R. (2001). "Three-Dimensional Model for Reservoir Sedimentation ", PhD Thesis, University of Newcastle.

[6]. Churchill, M.A. (1948). "Discussion on analysis and use of reservoir sedimentation data", Proc. of Federal Interagency Sedimentation Conference, 139-140.

[7]. Dendy, FE. (1974). "Sediment Trap Efficiency of Small Reservoirs." Trans. of ASAE, 17 (5), 898-988.

[8]. Gill, M.A. (1979). "Sedimentation and Useful Life of Reservoirs." J. Hydrology, 44, 89-95.

[9]. Heinemann, H.G. (1981). "A New Sediment Trap Efficiency Curve for Small Reservoirs." Bulletin for Water Resources , 17(5), 825-830.

[10]. Jothiprakash, V.,Garg, V. (2008). "Estimation of useful life of a reservoir using sediment trap efficiency." J. Spatial Hydrology, 8(2).

[11]. Jothiprakash, V.,Garg, V. (2008). "Re-look to Conventional Techniques for Trapping Efficiency Estimation of a Reservoir." Int . J. Sediment Res., 23 (1), 7684.

[12]. Morris, G. L., and Fan, J. (1998). Reservoir Sedimentation Handbook, McGraw Hill, New York, USA. 
[13]. Shangale A. K. (1991). "Reservoir Sedimentation Status in India", Jalvigyan Sameeksha, 5, 63-70.

[14]. Siyam A. M., Mirghani M., El zein S., Golla S., and El-sayed S. M. (2005). "Assessment of the current state of the Nile basin reservoir sedimentation problems." $N B C N$ $R E$, Research Cluster, Group-I Report.

[13]. USACE , (1989) "Sedimentation investigations of rivers and reservoirs."Int. J. Sediment Research, 23(1), 2008, 76-84 -83-

[14]. Verstraeten, G., Poesen, J.,(2000). "Estimating Trap Efficiency of Small Reservoirs and Ponds." Progress in Physical Geography, 24, 219-251.

[15]. Yang, X. (2003). Manual on Sediment Management and Measurement, Operational Hydrology Rep. No.47, WMO-No. 948, Geneva, Switzerland.

[16]. Yoon, Y. N. (1992). "The state and the perspective of the direct sediment removal methods." Int. J. Sediment Res., $7(20), 99-115$. 